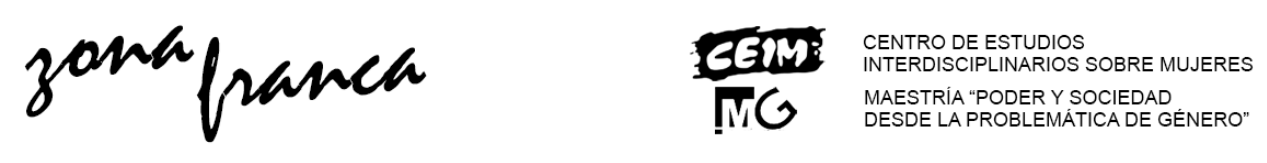

\title{
GRAMÁTICO, Karin; MARINI, Mariela y WECHSLER, Wanda (compiladoras). (2018). Historia Reciente, Género y Clase Trabajadora, Buenos Aires, Ediciones Imago Mundi, 126 pp., ISBN: 978-950-793-306-6
}

Ana Cecchi ${ }^{*}$

\section{Resumen}

Esta compilación surge en la Universidad Nacional Arturo Jauretche, Florencio Varela, en el marco del proyecto de investigación "Experiencias, luchas y memorias de trabajadores y trabajadoras en el pasado reciente argentino" y es el resultado del diálogo interdisciplinario sobre el pasado reciente, el mundo del trabajo y la categoría de género.

Palabras Clave: Género- historia reciente- clase trabajadora

El libro compilado por Gramático, Mariani y Wechsler, propone un recorrido conformado por cinco capítulos desarrollados por destacados referentes de las ciencias sociales y la historiografía para reflexionar sobre la historia reciente, la categoría de género y la clase trabajadora. Uno de los aciertos de esta publicación es la selección de los participantes, la tarea de curaduría realizada por las compiladoras que han logrado reunir en una misma unidad a los intelectuales más importantes de un campo que nació en los años ochenta en el marco de las transiciones pos dictatoriales del cono sur y que, desde entonces, se expandió como una problemática con identidad propia.

El primer capítulo se centra en la historia reciente como categoría de análisis. Débora D' Antonio y Ariel Eidelman dan cuenta de los debates sobre esta

* CONICET. Doctora en Historia.

Revista Zona Franca- Centro de estudios interdisciplinario sobre las mujeres (CEIM)- Maestría poder y sociedad desde la problemática de género (MG), Rosario, Argentina. ISSN, 2545-6504 http://zonafranca.unr.edu.ar/index.php/ZonaFranca| Numero 26 (2018). 
categoría y su periodización. Este capítulo condensa sus rasgos generales y establece ciertos consensos alcanzados que la centran en las décadas del 60 y del 70; dónde la dimensión política ha sido privilegiada por sobre otras dimensiones y dónde la experiencia traumática del terrorismo de estado configura un marco interpretativo. Los autores construyen la periodización del pasado reciente como un problema y analizan la conflictividad social como una variable en discusión. Privilegian como punto de inicio las insurrecciones obreras del 69 en Santa fe y Córdoba y cierran el período en 1982. La propuesta de periodización aquí esbozada se basa en una lectura del pasado que coloca el acento en la conflictividad por sobre otros factores. Observa las huelgas, los sabotajes y las movilizaciones desarrolladas desde el 69 como un tipo de conflictividad que se caracterizó por desbordar a los partidos políticos; por un enfrentamiento abierto con los poderes y las fuerzas represivas del estado y, en muchos casos, por la presencia de una vocación de transformación de la sociedad. El capítulo propone una unidad histórica contradictoria (1969-1982), articulada por dos fases. La primera abarca los seis años que van de 1969 a 1975 y se caracteriza por el ascenso obrero junto a la movilización de otros actores y una segunda fase desde mediados de 1975 muestra un reflujo o retroceso de los sectores sociales movilizados provocado por una persecución selectiva primero, y masiva después, y por el creciente despliegue de la violencia estatal. Además el capitulo establece una serie de temas de estudio del pasado reciente centrados en tres ejes: la violencia política de los grupos revolucionarios; la relevancia del estudio de la clase trabajadora del período como un objeto privilegiado y el auge de las 
temáticas de género y sexualidad. Por último el capítulo propone recaudos metodológicos con respecto a las fuentes, destacando la importancia de la historia oral tiene para abordar el período y la puesta en crítica de los reservorios documentales producidos durante esta conflictiva etapa.

Los capítulos 4 y 5 ponen el foco en dos casos que tienen a la clase trabajadora por objeto, durante la primera mitad de los años setenta y su relación con la militancia sindical. El capítulo 5 de Victoria Basualdo se centra en la primera mitad de los años setenta, período marcado por la radicalización del movimiento obrero de base a partir del caso de la fábrica textil y de calzado Alpargatas en Florencio Varela. Se muestra el proceso de organización sindical y militancia, tomando como vía de entrada la historia oral. El capitulo se inserta en una investigación más amplia e intenta reponer las tensiones y contradicciones entre militancia de base y jerarquía sindical. Basualdo habla de la dificultad dar voz a los obreros de base que no eran dirigentes sindicales, que ingresaron en 1973, y que establecían diferencias entre la base y los delegados que no solo no luchaban por mejores condiciones de trabajo sino que eran supervisores, eran cooptados por patronal. Los diversos testimonios ponen de manifiesto polisémicas definiciones y aspiraciones del papel de las organizaciones gremiales o sindicales. ¿Que era un delegado? ¿Que se esperaba que hiciera? Además el capítulo muestra la confrontación entre distintas corrientes sindicales, muchas veces acompañada de la proletarización de un conjunto de militantes políticos. Lo que puede verse a partir de las fuentes orales es que el núcleo central de la confrontación en la fábrica giraba en torno a las formas de concebir la tarea sindical y el rol de los 
delegados. Este análisis se vincula a la pregunta por el grado de burocratización y representatividad de la clase trabajadora de los primeros años setenta.

El caso abordado enel capítulo 4 por Federico Lorenz se detiene en un problema similar que busca reflexionar sobre el proceso de organización sindical en los astilleros Astarsa de Tigre, y trabaja el caso de la Agrupación Naval José María Alesio entre su surgimiento en 1973 y 1976. La agrupación nace tras la muerte del operario Alesio y lleva su nombre. Este capítulo que se configura como un triller retoma las acciones políticas de un grupo de 28 trabajadores militantes sindicales que a partir de Mayo de 1973 vivieron los años más intensos de sus vidas y que serán salvajemente derrotados. Lorenz pondera esta micro historia para echar luz sobre racionalidades políticas sentimientos y vínculos emotivos. Para este trabajo las entrevistas aparecieron como necesidad histórica y política. Los sentidos construidos por los militantes gremiales de esta agrupación y su relación con montoneros los configuran como un caso a micro escala para pensar los horizontes de expectativas y prácticas políticas a gran escala de la experiencia de la clase trabajadora en este período intenso. Este capítulo permite establecer que en los astilleros de Astarsa los obreros sufrieron represión y violencia creciente desde finales de 1973, por la santísima trinidad (la patronal, la burocracia sindical y las fuerzas represivas). En este sentido el planteo de Lorenz marca la temprana represión a los obreros de Astarsa en 1973, y la complicidad empresarial y burocrática con la última dictadura militar en la misma línea que otros trabajos propuestos por Victoria Basualdo que muestran aspectos cómplices y represivos en los años 74 y 75 .

Revista Zona Franca- Centro de estudios interdisciplinario sobre las mujeres (CEIM)- Maestría poder y sociedad desde la problemática de género (MG), Rosario, Argentina. ISSN, 2545-6504 http://zonafranca.unr.edu.ar/index.php/ZonaFranca| Numero 26 (2018). 
El capítulo 3 elaborado por Florencia Partenio desde las ciencias sociales retoma como objeto a la clase trabajadora, su praxis política e identitaria para organizarla en torno a la categoría de experiencia desde los estudios de género. La relación entre experiencia y agencia se despliega desde narrativas biográficas de mujeres en tres escenas singulares del mundo del trabajo: experiencias de una fábrica metalúrgica de Quilmes; la recuperación de una fábrica textil en "la sección enconado" entre 2003 y 2004 y la experiencia en una Metalúrgica recuperada en el 2003 organizan el centro de gravedad de experiencias de crisis del mundo salarial donde las mujeres se consolidaron como actores claves del proceso para la puesta en marcha de la recuperación fabril e identitaria.

Pero es tal vez el capítulo 2 de Alejandra Oberti, Entre generaciones: militancia y transmición donde de se condensan todas las líneas que aborda esta compilación en la medida en que recupera, como lo hacen el resto de los capítulos, la importancia de los testimonios, de los testigos, de las voces de los protagonistas. Oberti no habla de historia reciente sino de pasado reciente y diferencia el estudio de un problema de un período. Nos recuerda que los problemas y preguntas siempre se realizan en el presente "no se trata de buscar el pasado sino de buscar el pasado de nuestras verdades". Desde un denso andamiaje teórico que pasa por Foucault, Agamben y Ricoeur y por el concepto de espacio biográfico elaborado por Arfuch, Oberti discute con la tesis de Sarlo en Tiempo presente, cultura de la memoria y giro subjetivo para poner en escena que las memorias siempre se encuentran en conflicto. La memoria es la presencia de lo ausente y tanto la pérdida como el exceso de memoria producen un déficit de 
crítica y llevan a la repetición. El caso de estudio desarrollado por Oberti aborda la relación entre militancia, vida cotidiana y afectividad en las relaciones personales al interior de la familia militante. Tomando como ejemplo el Libro de Manuel, que Julio Cortázar escribe en 1972, su recorrido elabora el problema de la identidad y la narración entre mujeres madres, hijas, abuelas. Se detiene en Sandra U militante montonera de la Plata y Mar del Plata que tras el asesinato de su pareja, y embarazada, abandona su nombre de Guerra Ana, para cambiar de ubicación y de estrategia en su militancia. Para Oberti resulta de interés destacar que Sandra nombra a su hija con ese nombre del pasado presente, con ese signo identitario de su militancia pasada, de aquello que ella ya no es y pervive en su hija. Este caso la lleva a reflexionar sobre la militancia de María del Socorro Alonso cuya pareja Guille, es desaparecida en 1976, y que ella embarazada va a buscar con su suegra Pola en un vínculo que no es biológico, sino que es construido desde la angustia y el afecto. Cuando María queda embarazada nuevamente en 1980 le presenta a su niña a la abuela Pola, que lejos de ser la abuela biológica, es la abuela identitaria. Se trata de identidades descentradas, de madres que reelaboran las categorías tradicionales de madre, abuela e hija. Esta perspectiva establece que uno no siempre es el mismo; que los testimonios y la trasmisión de la memoria reciente no es mera repetición, que se compone de una trama discursiva que incluye la escucha y el silencio como dimensiones inseparables de mutables identidades colectivas en conflicto. 
Revista Zona Franca- Centro de estudios interdisciplinario sobre las mujeres (CEIM)- Maestría poder y sociedad desde la problemática de género (MG), Rosario, Argentina. ISSN, 2545-6504 http://zonafranca.unr.edu.ar/index.php/ZonaFrancal Numero 26 (2018). 